\title{
Advances in Medical Management of Cluster Headache
}

\author{
Stefan Evers, MD, PhD \\ Professor of Neurology and Clinical Neurophysiology, Department of Neurology, University of Münster
}

\begin{abstract}
Cluster headache is a rare but extremely disabling condition. For the acute treatment of cluster headache attacks, oxygen (100\%) with a flow of at least $71 /$ minute, $6 \mathrm{mg}$ subcutaneous sumatriptan, and $5 \mathrm{mg}$ zolmitriptan nasal spray are the drugs of first choice. Prophylaxis of cluster headache should be performed with verapamil in a daily dose of at least 240mg (maximum dose depends on efficacy and tolerability). Although no placebo-controlled trials are available, steroids are clearly effective in cluster headache. Methylprednisone (or equivalent corticosteroid) at least $100 \mathrm{mg}$ orally or up to $500 \mathrm{mg}$ intravenously per day over five days (then tapering down) is recommended. Methysergide, lithium, and topiramate are recommended as drugs of second choice. Although in part promising, surgical procedures require further scientific evaluation before they can be recommended.
\end{abstract}

\section{Keywords}

Cluster headache, sumatriptan, oxygen, zolmitriptan, verapamil, steroids, lithium, topiramate

Disclosure: The author has no conflicts of interest to declare.

Received: October 23, 2008 Accepted: June 15, 2009 DOI: 10.17925/USN.2009.05.01.75

Correspondence: Stefan Evers, MD, PhD, Department of Neurology, University of Münster, Albert-Schweitzer-Str. 33, 48129 Münster, Germany. E: everss@uni-muenster.de

The second edition of the headache classification from the International Headache Society (IHS) has defined a new primary headache grouping named the trigemino-autonomic cephalgias (TAC). ${ }^{1}$ All of these headache syndromes have two features in common: relatively short-lasting, unilateral, severe headache attacks, and, typically, accompanying cranial autonomic symptoms. These autonomic symptoms occur on the side of the headache and comprise lacrimation, conjunctival injection, rhinorrhea, miosis, and ptosis. The most important and prevalent of these headache disorders is cluster headache.

Cluster headache is defined as a paroxysmal, strongly unilateral, very severe headache, typically with a retro-orbital maximum of pain. The occurrence of cranial autonomic symptoms is obligatory, but can be replaced by restlessness/agitation. The attacks occur up to eight times a day, sometimes with a nocturnal preponderance, and last for between 15 and 180 minutes and, rarely, several hours. The episodic form of cluster headache occurs in $80 \%$ of cluster headache sufferers, with bouts lasting for between seven and 365 days separated by pain-free remission periods of Ionger than one month's duration. If the cluster attacks occur for longer than one year without remission periods or with remission periods lasting for less than one month, the diagnosis is chronic cluster headache. This is the case in 15-20\% of cluster headache sufferers. The two forms do not necessarily evolve from one another. The lifetime prevalence of cluster headache is about $0.1 \%$, with a mean male-to-female ratio of $4.3: 1 .^{2} \mathrm{~A}$ genetic background for cluster headache has not been described but is likely. ${ }^{3}$ Cluster headache can be seen even in children and in very old adults. ${ }^{4}$ There is a familial occurrence in $2-7 \%$ of cases. On average, the headaches start at 28-30 years of age, but they can start at any age; after 15 years, $80 \%$ of cluster headache patients still have attacks. ${ }^{5}$

\section{Treatment of Cluster Headache}

The treatment of cluster headache is based on empirical data rather than on a pathophysiological concept of this disorder. ${ }^{6}$ Drug treatment can be divided into acute attack abortion and prophylaxis. Non-drug treatment (except neuromodulation) is ineffective in nearly all patients.

\section{Attack Treatment}

The medical attack abortion is still most effectively performed by inhalation of pure (100\%) oxygen or by subcutaneous sumatriptan. There have been recent advances with intranasal triptans. However, the injection of sumatriptan is still unbeaten in terms of acute treatment and there is no drug in the pipeline promising similar efficacy. Oxygen should be inhaled for 20 minutes in a sitting, upright position with a face mask and with a flow of at least $7 \mathrm{l} /$ minute (sometimes more than $10 \mathrm{l} /$ minute is required). ${ }^{7.8}$ There are no contraindications known for the use of oxygen; it is safe and has no side effects. About $60 \%$ of all cluster headache patients respond to this treatment with significant pain reduction within 30 minutes.

In placebo-controlled trials, sumatriptan injected subcutaneously was effective in about $75 \%$ of all cluster headache patients (i.e. they were 


\section{Headache}

pain-free within 20 minutes). ${ }^{9,10}$ In daily practice, the responder rate is even higher. Sumatriptan is safe and has no side effects in most patients, even after frequent use. ${ }^{11,12}$ Contraindications are cardio- and cerebrovascular disorders and untreated arterial hypertension. The most unpleasant side effects are chest pain and distal paresthesia. In open prospective observational studies, even subcutaneous sumatriptan $3 \mathrm{mg}$ is effective in the majority of patients. ${ }^{13,14}$ In recent open and double-blind, placebo-controlled trials, sumatriptan nasal spray $20 \mathrm{mg},{ }^{15,16}$ oral zolmitriptan $10 \mathrm{mg},{ }^{17}$ and zolmitriptan nasal spray 5-10mg ${ }^{18,19}$ were also effective within 30 minutes. Intake of oral zolmitriptan 10mg is not really an alternative, but the nasal sprays should be tried after the inhalation of oxygen and before the subcutaneous injection of sumatriptan. Some patients can be advised to stratify their acute drug treatment, giving them the choice between oxygen, spray, and injection.

Oral ergotamine has been used in the treatment of cluster headache attacks for more than 50 years ${ }^{20-22}$ and is effective when given very early in the attack. However, more recent trials are lacking. The intranasal application of dihydroergotamine in cluster headache attacks was not superior to placebo. ${ }^{23}$ Recently, the intravenous application of dihydroergotamine $1 \mathrm{mg}$ over three days has been shown to be effective in the abortion of severe cluster attacks in an open retrospective trial. ${ }^{24}$

The nasal installation of lidocaine $(1 \mathrm{ml}$ with a concentration of $4-10 \%$; the head should be reclined by $45^{\circ}$ and rotated to the affected side by $30-40^{\circ}$ ) is effective in at least one-third of patients. ${ }^{25-28}$ The use of lidocaine evolved from early observations that cocaine is effective in aborting cluster headache attacks. This has been supported by a recent open, uncontrolled trial with $10 \%$ intranasal cocaine. ${ }^{28}$

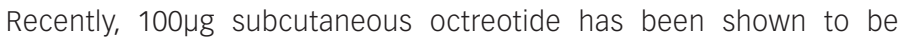
effective in the treatment of acute cluster headache attacks in a double-blind, placebo-controlled trial, ${ }^{29}$ confirming previous observations on the efficacy of parenteral somatostatin in cluster headache. However, these latter procedures are still experimental and cannot be recommended for clinical use.

The use of analgesics and specific acute drugs is generally safe in cluster headache even when very high doses are taken daily. However, recently it has been shown that patients with cluster headache can develop medication-overuse headache. ${ }^{30}$ This situation seems to be very rare and predominant in cluster headache patients with additional migraine or migraine in their family.

\section{Prophylactic Drug Treatment}

In the prophylactic treatment of cluster headache, no major advances have been made in the past 20 years. Verapamil at a daily dose of 240-960mg is still the first-choice drug in the prophylaxis of episodic and chronic cluster headache, ${ }^{31}$ although only a few sufficient doubleblind, placebo-controlled trials are available. Controlled trials comparing verapamil and lithium with placebo showed the efficacy of both substances, with verapamil having more rapid action. ${ }^{32,33}$ In some cases, a daily dose of more than 720mg can be necessary. Regular electrocardiogram (ECG) controls are required to control for a potential development of atrioventricular block and symptomatic bradycardia. ${ }^{34}$ Side effects of verapamil are bradycardia, edema, constipation, gastrointestinal discomfort, gingival hyperplasia, ${ }^{35}$ and, in particular, a dull headache. There is no optimal way of dosing verapamil. An increase of $80 \mathrm{mg}$ every three days is normally recommended. The full efficacy of verapamil can be expected within two to three weeks. In the first two weeks of verapamil administration, steroids are also administered by some clinicians.

The best alternative to verapamil is steroids, although there are no sufficient placebo-controlled trials for their use in cluster headache. All published reports demonstrate the efficacy of steroids given in different regimes. ${ }^{31}$ Steroids are recommended for short-term useover two to three weeks-when rapid control of attacks is desired. However, some patients are attack-free only under steroids, and rarely is continuous administration of steroids necessary. There is no evidence on which to base the use of steroids, although their high morbidity suggests caution, short courses, and avoidance in chronic cluster headache. To commence steroid treatment, prednisone 60-100mg given once a day for at least five days is recommended, with the dose then reduced by $10 \mathrm{mg}$ every day. At high doses, more than $80 \%$ of all cluster headache patients respond to steroids. Methylprednisone $500 \mathrm{mg}$ intravenously for up to five days can be even more effective.

Lithium (given as lithium carbonate) has been studied in cluster headache prophylaxis at a daily dose of between 600 and 1,500mg in more than 20 open trials. ${ }^{36}$ The improvement in chronic cluster headache was reported to be as high as 78\% (63\% in episodic cluster headache). However, a placebo-controlled trial did not show any efficacy of lithium in episodic cluster headache. ${ }^{37}$ Lithium should be monitored by the plasma level, which should be between 0.3 and $1.2 \mathrm{mmol} /{ }^{38}$ Regular checking of liver, renal, and thyroid function and electrolytes is required. Major side effects are hypothyroidosis, tremor, and renal dysfunction. In summary, the efficacy of lithium is based on very small and open studies, with the evidence being somewhat more convincing in chronic cluster headache.

Methysergide has been recommended as a prophylactic drug in episodic cluster headache..11 However, no placebo-controlled, double-blind studies are available. The number of patients who benefit from methysergide is between 20 and 73\%; the drug is more effective in episodic cluster headache. The doses applied in the open studies ranged from 4 to $16 \mathrm{mg}$. Methysergide can be given in a daily dose of up to $12 \mathrm{mg}$ (starting with $1 \mathrm{mg}$ per day). Since there is a small but significant incidence of pulmonary and retroperitoneal fibrosis, the continuous use of methysergide is limited to a maximum of six months.

Valproic acid has been studied in two open trials with acceptable results ${ }^{39,40}$ and in one controlled study in which it did not produce different results from placebo. ${ }^{41}$ The clinical experience is that valproic acid is generally ineffective in cluster headache, but it can be tried as a third-choice drug at a daily dose of between 5 and 20mg/kg bodyweight.

Open studies suggest that topiramate is effective in the prophylaxis of cluster headache, ${ }^{42,43}$ although one study showed only a minor, if any, 
effect of topiramate. ${ }^{44}$ The recommended dose is at least 100mg per day, with a starting dose of $25 \mathrm{mg}$. The main side effects are cognitive disturbances, paresthesias, and weight loss. Topiramate is contraindicated in nephrolithiasis.

The pre-emptive use of triptans in cluster headache remains controversial. Oral sumatriptan 100mg given three times daily was not effective in preventing cluster headache attacks in a placebocontrolled trial..$^{45}$ In open trials, $40 \mathrm{mg}$ eletriptan per day ${ }^{46}$ or $2.5-5 \mathrm{mg}$ naratriptan per day ${ }^{47}$ reduced the number of cluster headache attacks.

For the ipsilateral intranasal application of topical substances such as capsaicin and civamide, double-blind studies have been published suggesting efficacy in the prophylaxis of cluster headache. ${ }^{48,49}$ However, the irritating nature of the nasally applied treatment makes the 'blindness' of the patient doubtful.

Oral melatonin 10mg was effective in one double-blind, placebocontrolled study..$^{50}$ However, in cluster headache refractory to other medication, melatonin used open-label did not produce any additional efficacy. ${ }^{51}$ Notably, no sufficient evidence for the efficacy of botulinum toxin, ${ }^{52}$ transdermal clonidine, ${ }^{53}$ misoprostol, ${ }^{54}$ or hyperbaric oxygen inhalation ${ }^{55}$ in the prophylactic treatment of cluster headache has been obtained. These approaches offer nothing useful to patients with cluster headache.

\section{Interventional and Surgical Treatment}

The most promising (but still preliminary) advances in the treatment of cluster headache have been made in the field of neuromodulation. It has been observed that greater occipital nerve blockade resulted in a significant reduction of cluster headache attacks in about two-thirds of patients. ${ }^{56,57}$ This finding confirmed previous observations, but needs to be replicated in controlled trials. Suboccipital injection of long-acting steroids was also shown to be effective in the prophylaxis of cluster headache in a double-blind, placebo-controlled trial. ${ }^{58}$ These findings induced open clinical trials on occipital nerve stimulation in refractory cluster headache. These trials showed improvement in the majority of patients. ${ }^{59-61}$

If all drugs are ineffective, contraindicated, or not tolerated, and a secondary cluster headache has been excluded, surgical treatment may be suggested. Surgical procedures should be treated with great caution because no reliable long-term observational data are available, and some procedures can induce trigeminal neuralgia or anaesthesia dolorosa. ${ }^{62}$ Unlike in trigeminal neuralgia, surgical treatment of cluster headache is not a causal therapy, and continuation of cluster headache after the procedure can be observed. ${ }^{63}$ Recently, deep brain stimulation of the posterior inferior hypothalamus has been shown to be effective in the majority of several samples of patients with intractable cluster headache. ${ }^{64-67}$ Recommendations for the selection of patients for these procedures have been published recently; ${ }^{68}$ however, the clinical role of this procedure is yet to be determined.

\section{Conclusion}

Cluster headache has become a disorder that, although devastating in nature, can be treated effectively. Recent advances have been made in acute attack treatment by different types of triptan application. Prophylactic drug treatment, which for a long time used only verapamil, lithium, and steroids, has been extended by the introduction of antiepileptic drugs (valproic acid, topiramate). Much hope and promise has arisen from the advances in neurostimulation. The future will show whether these advances can be introduced into clinical practice.

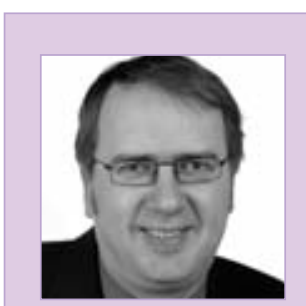

Stefan Evers, MD, PhD, is a Professor of Neurology and Clinical Neurophysiology and a Consultant in the Department of Neurology at the University of Münster. He is also Head of the Headache and Epilepsy Clinics at the same institution. Professor Evers is Vice President of the German Migraine and Headache Society and Chair of the Headache Panel of the European Federation of Neurological Societies.
1. Headache Classification Committee of the International Headache Society, Cephalalgia, 2004;24(Suppl. 1):1-160.

2. Fischera $\mathrm{M}$, et al., Cephalalgia, 2008;28:614-18.

3. Russell MB, Lancet Neurol, 2004;3:279-83.

4. Evers S, et al., Cephalalgia, 2002;22:160-62.

5. Bahra A, et al., Neurology, 2002;58:354-61.

6. May A, Leone M, Curr Opin Neurol, 2003;16:333-40.

7. Kudrow L, Headache, 1981;21:1-4.

8. Fogan L, Arch Neurol, 1985;42:362-3

9. The Sumatriptan Cluster Headache Study Group, N Eng/ J Med, 1991;325:322-6.

10. Ekbom K, et al., Acta Neurol Scand, 1993:88:63-9.

11. Ekbom K, et al., Cephalalgia, 1995;15:230-36.

12. Göbel H, et al., Neurology, 1998;51:908-11.

13. Krabbe A, Cephalalgia, 1989;9(Suppl. 10):404-5

14. Gregor N, et al., Headache, 2005;45:1069-72.

15. Schuh-Hofer S, et al., J Neurol, 2002;249:94-9.

16. Van Vliet JA, et al., Neurology, 2003;60:630-33.

17. Bahra A, et al., Neurology, 2000;54:1832-9.

18. Cittadini, et al., Arch Neurol, 2006;63:1537-42.

19. Rapoport AM, et al., Neurology, 2007:69:821-6.

20. Horton BT, et al., Mayo Clin Proc, 1948;23:104-8.

21. Kunkle EC, et al., Trans Am Neurol Assoc, 1952;77:240-43.

22. Friedman AP, Mikropoulos HE, Neurology, 1958;8:653-63.
23. Andersson PG, Jespersen LT, Cephalalgia, 1986;6:51-4.

24. Magnoux E, Zlotnik G, Headache, 2004;44:249-55.

25. Kittrelle JP, et al., Arch Neurol, 1985;42: 496-8.

26. Mills TM, Scoggin JA, Ann Pharmacother, 1997;31:914-15.

27. Robbins L, Headache, $1995 ; 35: 83-4$

28. Costa A, et al., Cephalalgia, 2000;20: 85-91.

29. Matharu MS, et al., Ann Neurol, 2004;56:488-94.

30. Paemeleire K, et al., Neurology, 2006;67: 109-13.

31. May A, et al.; EFNS Task Force, Eur J Neurol, 2006;13;1066-77.

32. Bussone G, et al., Headache, 1990;30:411-17.

33. Leone M, et al., Neurology, 2000;54:1382-5.

34. Cohen AS, et al., Neurology, 2007;69: 668-75.

35. Matharu MS, et al., J Neurol Neurosurg Psychiatry, 2005;76:124-7.

36. Ekbom K, Headache, 1981;21:132-9.

37. Steiner TJ, et al., Cephalalgia, 1997;17:673-5.

38. Manzoni GC, et al., Cephalalgia, 1983;3:109-14.

39. Gallagher RM, et al., J Am Osteopath Assoc, 2002;102:92-4.

40. Hering R, Kuritzky A, Cephalalgia, 1989;9:195-8.

41. El Amrani $\mathrm{M}$, et al., Cephalalgia, 2002;22:205-8.

42. Förderreuther S, et al., Cephalalgia, 2002;22:186-9.

43. Láinez MJ, et al., Headache, 2003;43: 784-9.

44. Leone M, et al., Cephalalgia, 2003;23:1001-2.

45. Monstad I, et al., Headache, 1995;35:607-13.

46. Zebenholzer K, et al., Headache, 2004; 44:361-4.
47. Mulder LJ Spierings EL, Cephalalgia, 2002:22:815-17.

48. Marks DR, et al., Cephalalgia, 1993;13:114-16.

49. Saper JR, et al., Arch Neurol, 2002:59:990-94.

50. Leone M, et al., Cephalalgia, 1996;16:494-6.

51. Pringsheim T, et al., Headache, 2002;42:787-92.

52. Evers S, Curr Opin Otolaryngol Head Neck Surg, 2004;12:197-203.

53. Leone M, et al., Headache, 1997;37:559-60.

54. Evers S, et al., Headache, 1998:38:618-20.

55. Nilsson Remahl Al, et al., Cephalalgia, 2002;22:730-39.

56. Anthony M. In: Rose C (ed.), Migraine, Basel: Karger, 1985: 169-73.

57. Peres MF, et al., Cephalalgia, 2002:22:520-22.

58. Ambrosini A, et al., Pain, 2005;118:92-6.

59. Magis D, et al., Lancet Neurol, 2007;6:314-21.

60. Burns B, Lancet, 2007;369:1099-1106.

61. Schwedt TJ, et al., Cephalalgia, 2007;27:153-7.

62. Ekbom K, Solomon S. In: Olesen J, Tfelt-Hansen P, Welch KMA (eds), The Headaches, Philadelphia: Lippincott, 2000;731-40.

63. Matharu MS, Goadsby PJ, Brain, 2002:125:976-84.

64. Franzini A, et al., Neurosurgery, 2003;52: 1095-1101.

65. Schoenen J, et al., Brain, 2005;128:940-47.

66. Starr PA, et al., J Neurosurg, 2007;106:999-1005.

67. Bartsch T, et al., Cephalalgia, 2008;28: 285-95.

68. Leone $\mathrm{M}$, et al., Cephalalgia, 2004;24:934-7. 